\title{
Erythropoietin Sustains Cognitive Function and Brain Volume after Neonatal Stroke
}

\author{
Fernando F. Gonzalez ${ }^{a}$ Regina Abel ${ }^{d, e} \quad$ C. Robert Almli ${ }^{d-f}$ Dezhi Mu ${ }^{\text {b, g }}$ \\ Michael Wendland $^{c}$ Donna M. Ferriero ${ }^{a, b}$ \\ Departments of a Pediatrics, ${ }^{b}$ Neurology and ${ }^{\mathrm{c} R a d i o l o g y, ~ U n i v e r s i t y ~ o f ~ C a l i f o r n i a, ~ S a n ~ F r a n c i s c o, ~ C a l i f ., ~}$ \\ ${ }^{\mathrm{d}}$ Departmental Neuropsychobiology Laboratory, ${ }^{\mathrm{e}}$ Program in Occupational Therapy, and ${ }^{\mathrm{f}}$ Department of \\ Neurology, Washington University School of Medicine, St. Louis, Mo., USA; ${ }^{9}$ Department of Pediatrics, \\ West China Second Hospital, Sichuan University, Chengdu, China
}

\section{Key Words}

Neonatal hypoxic-ischemic injury $\cdot$ Neonatal brain injury . Stroke $\cdot$ Cognitive function

\begin{abstract}
Neonatal stroke leads to mortality and severe morbidity, but there currently is no effective treatment. Erythropoietin (EPO) promotes cytoprotection and neurogenesis in the short term following brain injury; however, long-term cognitive outcomes and optimal dosing regimens have not been clarified. We performed middle cerebral artery occlusion in postnatal day 10 rats, which were treated with either a single dose of EPO (5 $\mathrm{U} / \mathrm{g}$, i.p.) immediately upon reperfusion, or 3 doses of EPO (1 U/g, i.p. each) at $0 \mathrm{~h}, 24 \mathrm{~h}$, and 7 days after injury. At 3 months after injury, rats treated with 3 doses of EPO did not differ from shams in the Morris water maze, and generally performed better than either rats treated with a single dose or vehicle-treated injured rats. These multipledose-treated rats also had increases in hemispheric volume and its subregions. These results suggest that additional, later doses of EPO may be required for cell repair, proliferation, and long-term incorporation into neural networks after neonatal brain injury.

Copyright $\odot 2009$ S. Karger AG, Basel
\end{abstract}

\section{Introduction}

Stroke occurs in approximately 1 in 4,000 live fullterm births [1]. It is associated with significant morbidity and mortality, with death occurring in over $10 \%$ of newborns. Approximately $75 \%$ of survivors exhibit changes in central nervous system development with long-term neurological deficits such as epilepsy, cerebral palsy, and other motor and cognitive disabilities [2]. Despite these lifelong effects, no accepted postinjury treatment strategy exists.

It is clear from both neuroimaging studies and rodent models that damage does not occur just at the time of injury, but continues to evolve over a period of days to weeks [3]. This likely involves a variety of mechanisms responsible for cell death and decreased cell proliferation in both the core and penumbral tissue. Protection and repair of this damaged tissue would require suppression of cell death signals, as well as enhancement of cell proliferation and differentiation, over this prolonged period of time. Multiple therapies have been studied in an effort to suppress the toxic cascades that result in cell death and enhance the endogenous neurogenesis that occurs after injury, with the hope of increasing long-

\section{KARGER}

(ㄷ) 2009 S. Karger AG, Basel

Fax +41613061234

E-Mail karger@karger.ch

www.karger.com
Fernando F. Gonzalez, MD

Neonatal Brain Disorders Laboratory, University of California, San Francisco 521 Parnassus Avenue, C215

San Francisco, CA 94143-0663 (USA)

Tel. +1 415502 5822, Fax +1 415502 5821, E-Mail gonzalezf@peds.ucsf.edu 
term survivability of neurons and functional performance.

Erythropoietin (EPO) is a $34-\mathrm{kDa}$ glycoprotein that was originally identified for its role in erythropoiesis, but has since been found to have a variety of other roles. The pleiotropic functions of this cytokine include modulation of the inflammatory and immune responses [4-6], vasogenic and proangiogenic effects through its interaction with vascular endothelial growth factor (VEGF) [7, 8], as well as effects on central nervous system development and repair. EPO and EPO receptor (EPO-R) are expressed by a variety of different cell types in the central nervous system with changing patterns during development $[9$, 10]. EPO and EPO-R expression in both the rodent and human nervous system is elevated during gestation, but declines after birth [11]. Following injury, EPO and EPO$\mathrm{R}$ expression increases, with a variety of cell types expressing EPO and EPO-R following brain injury $[9,10]$, including neurons, astrocytes, endothelial cells, and microglia. These findings suggest that EPO has an important role in neurodevelopment, and may also play a prominent role in repair following brain injury in the neonate.

Recent evidence suggests that exogenously administered EPO has a protective effect in a variety of different causes of brain injury [12-14]. In adult rodent models, $\mathrm{EPO}$ has been found to protect neurons from ischemia in vitro [15], as well as reduce infarct volume following transient focal ischemia [16] and permanent ischemia [9] in vivo. In newborn rodents, pretreatment with EPO before injury has a protective effect $[13,17-21]$. In addition, postinjury treatment protocols have demonstrated both short- and long-term histological and behavioral improvement. A single dose of exogenous EPO administered immediately after neonatal hypoxic-ischemic injury in rats significantly reduced infarct volume and improved long-term spatial memory after injury [22]. Single- and multiple-dose treatment regimens of EPO following neonatal focal ischemic stroke in rats also reduced infarct volume in a dose-dependent manner [23], and demonstrated short-term improvement in sensorimotor outcomes [24].

We have previously described a nonhemorrhagic ischemic stroke model in the immature rat using transient middle cerebral artery occlusion (MCAO) $[25,26]$, which can be used for testing treatment strategies for neonatal stroke. The most important effect of an adequate neuroprotective therapy is improved long-term functional performance, as an indicator of neurologic function. While other studies have presented a promising role for EPO in neuroplasticity following brain injury, the exact dosage, number of doses, and time course have not been determined for long-term improvements in functional performance after stroke. Therefore, we performed long-term analysis of infarct size and cognitive function with visuospatial learning and memory testing following singleand multiple-dose treatment regimens in rats that underwent focal ischemia-reperfusion via neonatal MCAO.

\section{Methods}

All animal research was approved by the University of California, San Francisco Institutional Animal Care and Use Committee, and the Washington University Medical School Animal Studies Committee and Division of Comparative Medicine with the relevant National Institutes of Health guidelines. Every effort was made to minimize animal suffering and to reduce the number of animals used.

\section{Cerebral Focal Ischemia-Reperfusion}

All surgical procedures were performed in 10-day-old SpragueDawley rats; this age was chosen to approximate the development of the term human newborn [27]. Female rats with an 8- to 9-dayold litter (approx. 10 pups per litter) were bought from Simonson Labs (Gilroy, Calif., USA). Mothers were housed in a temperatureand light-controlled facility and given food and water until pups were 10 days old. Transient focal cerebral ischemia was produced using the MCAO method with some modifications $[25,26]$. Briefly, each pup was weighed and anesthetized with $3 \%$ isoflurane in a mixture of $70 \% \mathrm{~N}_{2} \mathrm{O}$ and $30 \% \mathrm{O}_{2}$. Following induction of anesthesia, $1.5 \%$ isoflurane was maintained and rectal temperature was monitored and maintained at $36-37^{\circ} \mathrm{C}$ with a combination of heating blanket and overhead light. With the animal supine, the right common carotid artery, external carotid artery, and internal carotid artery were exposed with a midline cervical incision. The pterygopalatine, occipital, superior thyroid, maxillary, and lingual arteries were coagulated. After ligation of the external carotid artery, a 5-0 nylon monofilament suture with blunted tip was inserted into the external carotid artery lumen and gently advanced through the internal carotid artery up to the middle cerebral artery until slight resistance was felt. Sham controls did not have the suture advanced. After placement of the suture, the wound was closed. Following MRI, reperfusion was achieved after $45 \mathrm{~min}$ of occlusion by removing the suture under isoflurane anesthesia. In a previous study, we found that an occlusion time of 45 min produced a moderate level of injury involving the ipsilateral striatum and parietotemporal cortex, and reperfusion was confirmed with contrast study [24]. Following surgery, animals were recovered from the anesthesia and returned to the dam until weaning.

\section{Magnetic Resonance Imaging}

Each animal was examined by diffusion-weighted spin echo planar imaging at 25-30 min after MCAO. The entire brain was imaged with serial 2-mm-thick coronal sections as previously described [25] using the following pulse sequence settings: TR/ $\mathrm{TE}=5,000 / 60 \mathrm{~ms}, 4$ averages, field of view $=35 \mathrm{~mm}$, data ma- 
Fig. 1. Experimental study design.

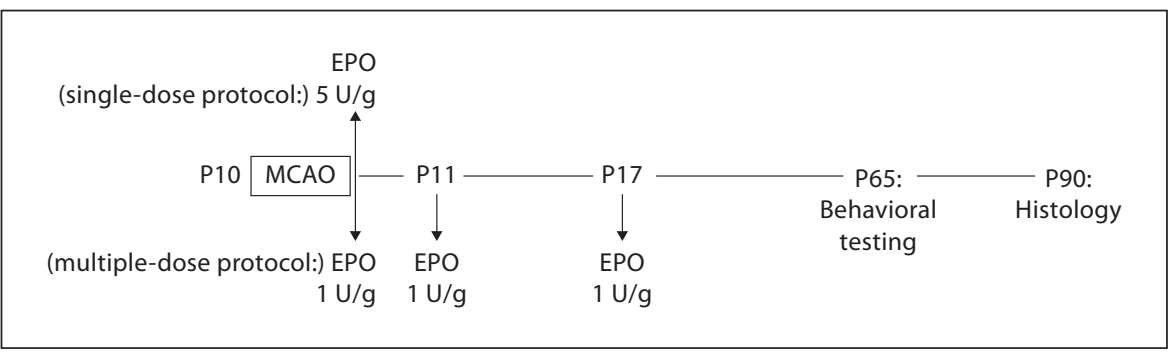

trix $=128 \times 128$, diffusion gradient duration $=20 \mathrm{~ms}$, separation $=29.7 \mathrm{~ms}$, amplitude $=70 \mathrm{mT} / \mathrm{m}, \mathrm{b}$-factor $=1,045 \mathrm{~s} / \mathrm{mm}^{2}$. Animals that exhibited ischemic injury in atypical regions, such as the brain stem, or that showed lack of cortical involvement were excluded from the study.

\section{EPO Treatment}

Immediately upon reperfusion, either vehicle $[0.1 \%$ bovine serum albumin (Sigma, St. Louis, Mo., USA) in saline] or recombinant human EPO (a gift from Johnson and Johnson) was injected intraperitoneally. In the single-dose EPO group, treatment rats received EPO at a dose of $5 \mathrm{U} / \mathrm{g}$ of body weight. In the 3 -dose EPO group, treatment rats received an initial dose of $1 \mathrm{U} / \mathrm{g}$ at reperfusion, followed by repeat doses of $1 \mathrm{U} / \mathrm{g}$ at $24 \mathrm{~h}$ and 7 days after injury (fig. 1). Sham animals were injected with either single or multiple doses of vehicle or EPO, at the same schedule, following sham surgery. Following surgery, animals recovered from anesthesia and were returned to their dam until weaning. Most pups that received MCAO at postnatal day 10 (P10) showed poor suckling during the first 2-3 days following surgery and were gavage fed, with daily weights measured for the first week to ensure adequate weight gain.

\section{Behavioral Testing: Visual/Spatial Learning and Memory}

Behavioral testing was initiated when rats reached 65 days of age. Morris water maze testing was performed in a room with distinctive, extra-maze navigational cues. Rats were placed in a tank (diameter $\mathrm{r}=1.12 \mathrm{~m}$, depth $=0.58 \mathrm{~m})$ with water $\left(23 \pm 1^{\circ} \mathrm{C}\right)$ made opaque with nontoxic paint, and 1 of 2 cylindrical escape platforms (visible or submerged). Videomax Water Maze Program (Columbus Instruments) was used to collect data. For the acquisition trials in the place condition, rats were released from a semi-randomly assigned quadrant and allowed $1 \mathrm{~min}$ to escape to a platform that was painted white and submerged below the water surface. The platform remained in quadrant 1 for all of the acquisition trials, and escape latency (time from release to escape on the platform) was recorded. Following each day's acquisition trials in the place condition, a retention trial was performed for the place condition where the escape platform was removed and the probe time [time the rat spent in the quadrant (quadrant 1) that previously contained the escape platform] and number of annulus crossings (number of times the rat crossed the actual location/ place that the platform had occupied during acquisition trials) were compiled from computer data. Rats performed 6 1-min acquisition trials and 1 1-min retention trial per day. Rats were also tested in a cue, or vision and motor ability control condition, where the escape platform was painted black and extended above the water line. Finally, there was a random, or no spatial contingency condition, where the white escape platform was submerged below the water line and moved randomly between the 4 quadrants on each acquisition trial of each day.

\section{Histology}

For histopathological examination, following behavioral testing, animals were anesthetized with sodium pentobarbital (100 mg/kg; Nembutal, Abbott Labs, Abbott Park, Ill., USA) and sacrificed at approximately $3-4$ months of age by transcardiac perfusion with ice-cold $4 \%$ paraformaldehyde in $0.1 \mathrm{M}$ phosphate-buffered saline ( $\mathrm{pH}$ 7.4). Brains were carefully removed and postfixed overnight, equilibrated in $30 \%$ sucrose in $0.1 \mathrm{M}$ phosphate-buffered saline and left at $4^{\circ} \mathrm{C}$ in $0.1 \mathrm{M}$ phosphate buffer with $0.1 \%$ sodium azide for a maximum of 2 weeks and then stored in cryoprotectant at $-20^{\circ} \mathrm{C}$ until staining. The mounted sections were air-dried, stained with cresyl violet, dehydrated in graded ethanol solutions, cleared in Citrisolv (Fisher Scientific, Pittsburgh, Pa., USA) and coverslipped in Permount (Fisher Scientific).

Stereological Volumetric Analyses of Regional Brain Volumes

Using systemic random sampling, a series representing every 12 th section was selected, cresyl violet stained, and analyzed. Sections encompassed the whole brain rostrally from the genu of the corpus callosum through the posterior portion of the hippocampus to the occipital lobes caudally. All volumetric quantifications were performed with Nikon Eclipse E600 photomicroscope equipped with a high-resolution CCD camera, a motorized XYZ axis computer-controlled stage, and Neurolucida and Neuroexplorer morphometry software package (MicroBrightField, Inc., Colchester, Vt., USA). When calculating the volume, the crosssectional area of the region of interest (ROI) in each section was traced on the computer screen at low power using a $2 \times / 4 \times$ lens and the volume of the ROI was calculated according to the Cavalieri principle [28]. For the ROI, the right and left hemisphere, neocortex, striatum, hippocampus, and primary visual cortices were traced. Morphological criteria were used consistently in all animals to determine the boundaries of the ROIs. For example, for the hippocampus the entire dentate gyrus and CA regions were outlined, corresponding to figures 47-89 of the Paxinos Rat Brain Atlas [29]. For the primary visual cortex, the entire region was outlined from initiation through the extent of possible posterior sectioning of the brain, corresponding to figures 70-100. Damage due to stroke was determined quantitatively by calculating the percent preserved volume in the ipsilateral, or lesioned, hemisphere versus the contralateral, control hemisphere. 
Data Analysis

Data are presented as mean \pm SD. Repeated-measures analyses of variance were performed on escape latencies, probe times, and annulus crossings averaged across trials (as appropriate) within test days with factors treatment $\times$ days. For volumetric analysis, one-way analysis of variance was performed. Post hoc analyses were performed using the Tukey HSD and NewmanKeuls tests as appropriate. Pearson's or Spearman's correlation coefficient was used to analyze the relationship between brain volume and behavioral performance as appropriate. $\mathrm{p}$ values below 0.05 were considered significant. All statistical analyses were performed using StatView (version 5.0.1, SAS software, Cary, N.C., USA).

\section{Results}

A total of 40 rats underwent transient MCAO that fulfilled the inclusion criteria by MRI, and 26 underwent sham surgery. Rats were randomly allocated to MCAO with single-dose vehicle $(\mathrm{VO}-1, \mathrm{n}=8)$, MCAO with threedose vehicle (VO-3, $\mathrm{n}=11$, MCAO with single-dose EPO $(\mathrm{EPO}-1, \mathrm{n}=9$ ), and MCAO with three-dose EPO (EO-3, $\mathrm{n}=12$ ) groups. For sham animals, rats were assigned to single-dose EPO (ES-1, $\mathrm{n}=7$ ), single-dose vehicle (VS-1, $\mathrm{n}=7$ ), three-dose EPO (ES-3, $n=6$ ), and three-dose vehicle (VS-3, $\mathrm{n}=6$ ) groups. Sham groups did not statistically differ from one another and were combined for behavioral and histological analyses. In addition, there were no statistically significant differences between VO-1 and VO-3 groups, and those groups were combined to a single VO group for analysis. Male and female rats were evenly distributed between the groups, with no statistical significance between males and females in any of the analyses (data not shown).

\section{Spatial Learning and Memory}

For the escape latency in the place condition, shamtreated rats escaped to the hidden platform more quickly than either VO or EPO-1 rats (fig. 2a). In all groups, there was some improvement over the 6 days of testing, consistent with learning that a platform for escape exists somewhere within the water maze. EO-3 rats did not differ from shams, and there was a trend toward improvement with 3 doses of EPO versus single-dose or vehicle treatment, but it was not quite significant $(\mathrm{p}=0.10)$.

Following removal of the platform for the probe trial, EO-3 rats did not differ from shams and spent more time in the escape quadrant that had previously contained the escape platform compared to either VO or EO-1 groups $(\mathrm{p}<0.02)$ (fig. 2b). Similarly, EO-3 rats did not differ from shams and generally crossed the previous platform loca-
Table 1. Correlations of regional brain volumes with water maze performance

\begin{tabular}{llll}
\hline Region & Test & $\mathrm{R}$ & p value \\
\hline Neocortex & escape latency - place & 0.454 & $<0.03$ \\
& probe time & 0.442 & $<0.01$ \\
& escape latency - cue & 0.592 & $<0.001$ \\
Striatum & annulus crossings & 0.483 & $<0.01$ \\
& escape latency - place & 0.484 & $<0.01$ \\
& escape latency - cue & 0.578 & $<0.01$ \\
Hippocampus & annulus crossings & 0.475 & $<0.01$ \\
& escape latency - place & 0.400 & $<0.02$ \\
& escape latency - cue & 0.624 & $<0.01$ \\
Visual cortex & annulus crossings & 0.443 & $<0.04$ \\
& escape latency - place & 0.462 & $<0.03$ \\
& probe time & 0.400 & $<0.02$ \\
& escape latency - cue & 0.561 & $<0.01$ \\
& annulus crossings & 0.466 & $<0.01$ \\
\hline
\end{tabular}

tion more often than other injured groups during the probe trial, which approached significance $(\mathrm{p}=0.05)$ (fig. 2d).

To more accurately assess vision- and motor-based performance, the cue condition was used to measure escape latency to a visualized platform. Once again sham animals performed significantly better than VO animals and did not differ from EO-3 animals, who also performed significantly better than VO or EO-1 animals $(\mathrm{p}<0.02)$ (fig. $2 \mathrm{c})$. There was no difference in escape latency of rats in the random condition between any groups (data not shown).

\section{Injury Assessment}

Animals that received transient MCAO had significant tissue loss at this late time point after injury (fig. 3). In animals that underwent sham surgery, there was no difference in hemispheric volume between vehicle and EPO treatment. In the VO group, there was a significant decrease in the ratio of hemispheric brain volume (fig. 3c). No difference was observed between the EPO-1 group and $\mathrm{VO}$ animals, but tissue loss was significantly reduced in the EO-3 group, demonstrating a marked protective effect.

To better assess the effects of EPO on brain volumes, regional brain volumes were also calculated in rats treated with 3 doses (fig. 4). The volume of the neocortex and visual cortex did not differ between EO-3 and sham rats, and EO-3 rats also had significant increases in the volumes of the striatum, hippocampus, neocortex, and visual cortex compared to VO-treated rats. In addition, sig- 

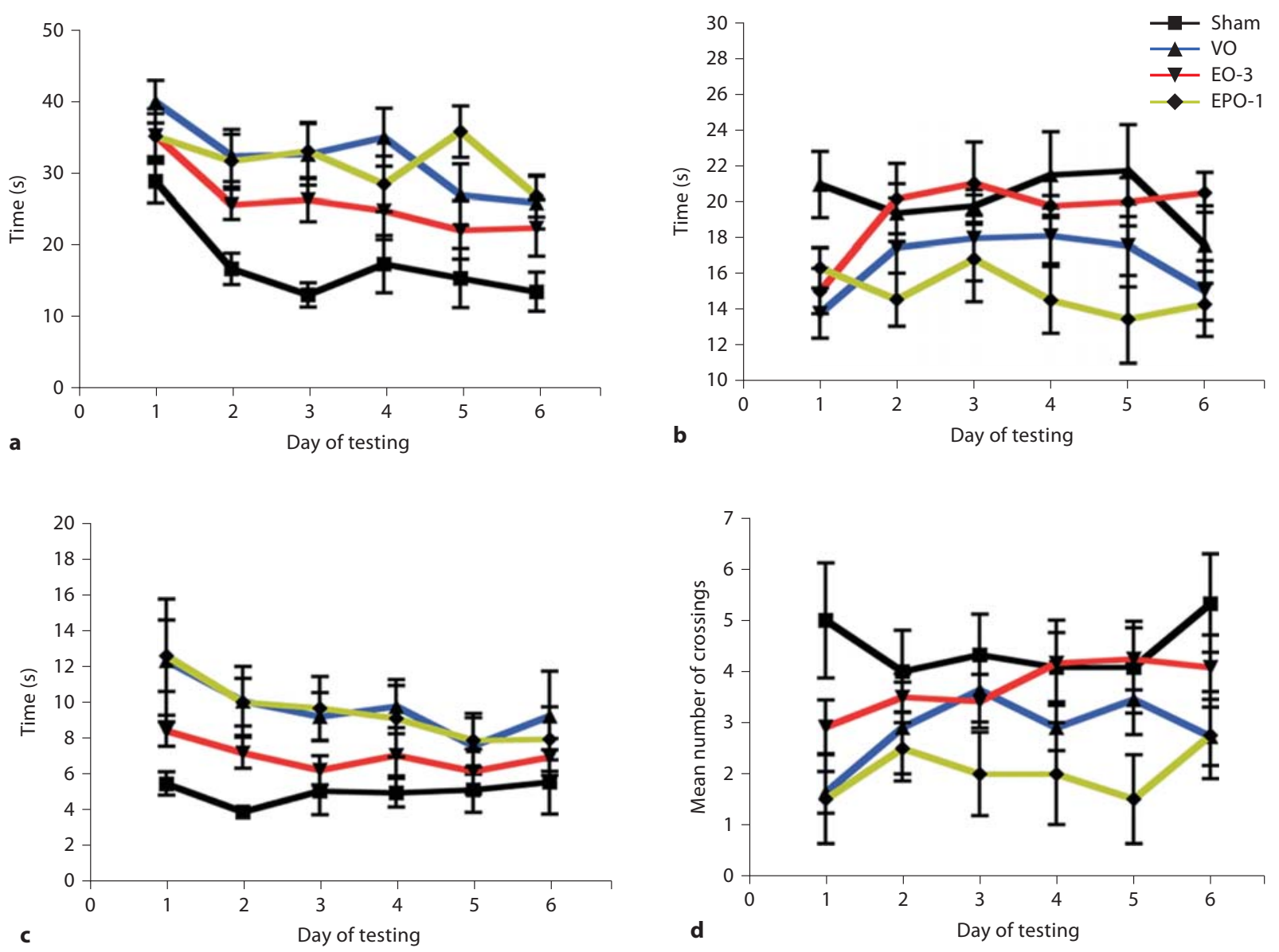

Fig. 2. Acquisition (escape latency) and retention (probe time, annulus crossings) trials for testing spatial learning and memory between $\mathrm{P} 65$ and $\mathrm{P} 90$ after MCAO at P10. Mean \pm SD raw escape latency and probe time data in seconds, averaged across daily trials, during water maze trials for the sham, VO, EPO-1, and EO-3 groups. a Escape latency in the place condition. Injury significantly impaired spatial learning performance, but EO-3 rats did not differ from shams. There was also a trend for EO-3 rats to perform better compared to VO and EPO-1 rats $(p=0.10)$. b Probe time (retention trials) in the place condition. EO-3 rats had improved spatial memory, spending more time in the probe quadrant during retention trials that had previously contained the es-

nificant correlations were found in the size of regional brain volumes and functional performance (table 1). For example, the neocortical volume correlated with both memory- (probe time, annulus crossings) and vision- and motor-based components (cue) of the water maze, while striatal and hippocampal volumes correlated with learning- and memory-based performance.

\section{Discussion}

The results of this study demonstrate that, while a single dose of exogenous EPO immediately following transient MCAO did not preserve tissue volume in the long term, 3 doses of EPO did improve histology, with increased regional and total hemispheric brain volumes. In 


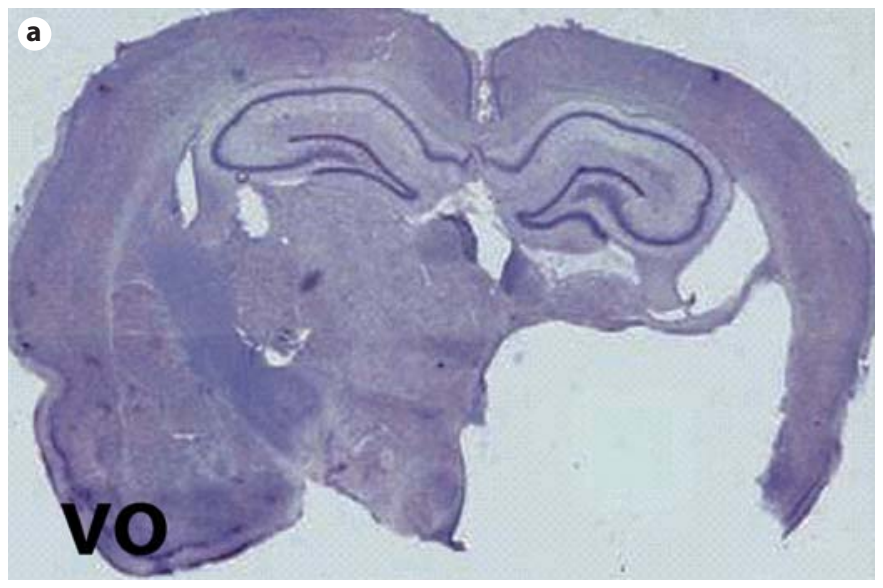

Fig. 3. Histological analysis at 3-4 months after injury. a VO animal, with injury and volume loss in the ipsilateral striatum and parietotemporal cortex. Small hole on the left side used to identify the contralateral hemisphere. b EO-3 animal, with marked improvement in hemispheric brain volume. c Ratio of ipsilateral (injured) to contralateral (uninjured) hemispheric brain volume. Injured animals with vehicle or single-dose EPO demonstrate significant decrease in volume ratio, but EO-3 animals show improvement ( ${ }^{\mathrm{a}} \mathrm{p}<0.05$ vs. sham, EO-3; ${ }^{\mathrm{b}} \mathrm{p}<0.05$ vs. VO, EPO-1).
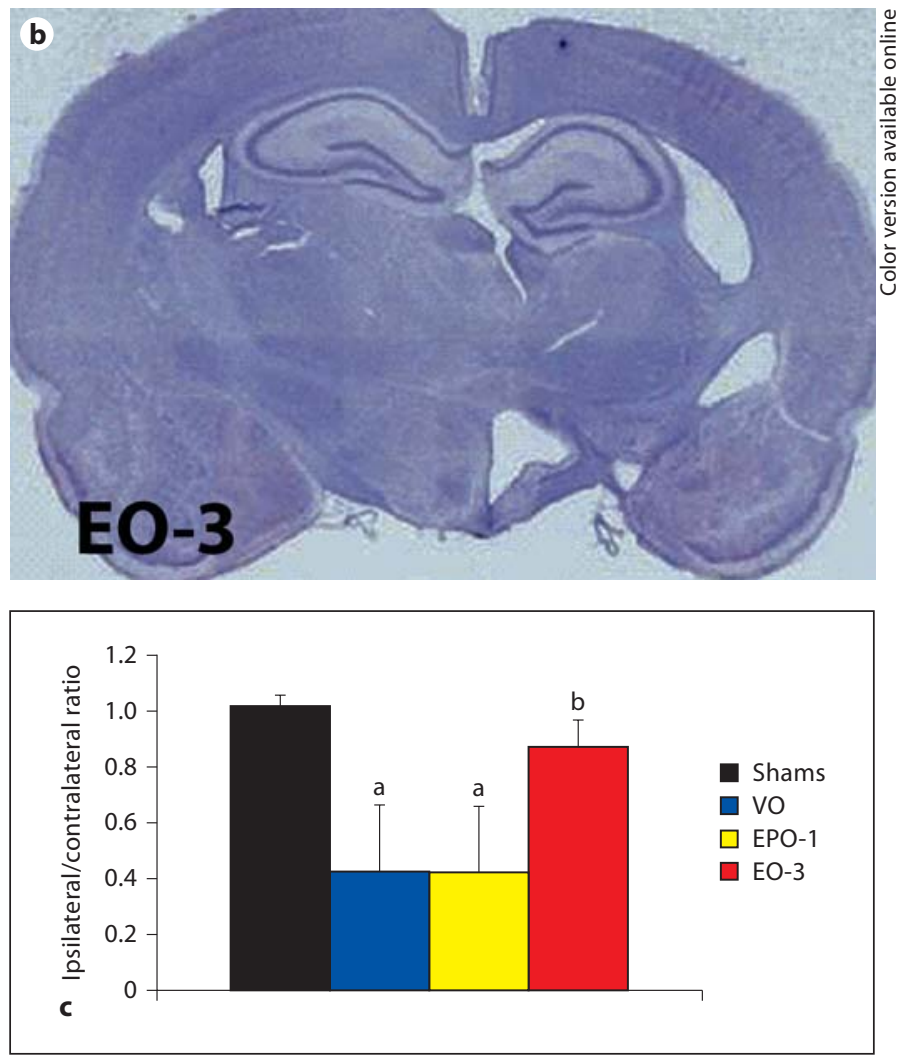

addition, these histological findings correlated with behavioral performance, with multiple-dose-treated rats not differing from shams and performing better in most components of spatial learning and memory performance.

EPO has previously been shown to preserve brain volume following neonatal hypoxia-ischemia $[13,18$, 22], and to decrease infarct volume following transient MCAO in P7 rats [23]. We have previously demonstrated that $\mathrm{P} 10$ rats treated with a single dose of EPO following $\mathrm{MCAO}$ had an increase in hemispheric brain volume and improved sensorimotor function at 2 weeks after injury [24]. We initially chose a single dose of EPO immediately following injury, as opposed to during or prior to injury, to more closely approximate a clinical scenario where EPO may be used for treatment. Similarly, this treatment regimen resulted in a marked increase in hemispheric brain volume and increased neurogenesis in the striatum of injured rats at 6 weeks after injury, possibly also demonstrating a proliferative and reparative effect [30].

While these results for single-dose EPO suggest a role for EPO in cell survival and repair, this may not be sufficient for long-term improvement. At later time points

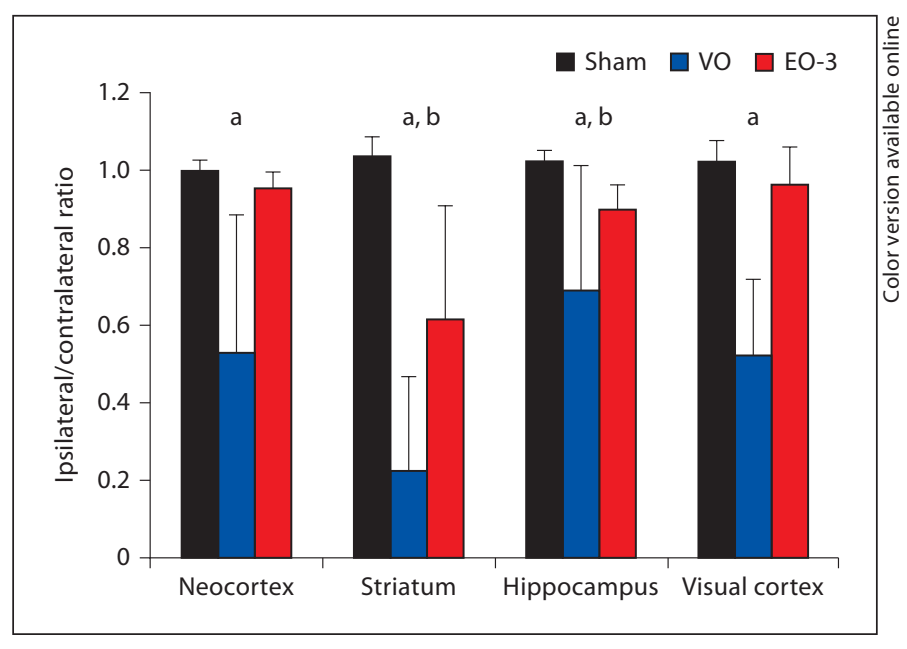

Fig. 4. Regional brain volumes in multiple-dose-treated rats. VO animals had significant decreases in all measured brain regions. EO-3 animals had significant improvement in regional brain volumes compared to VO animals, and did not differ from shams in neocortical or visual cortical volume ( ${ }^{\mathrm{a}} \mathrm{p}<0.05 \mathrm{vs}$. VO; ${ }^{\mathrm{b}} \mathrm{p}<0.05$ vs. sham). 
after injury, this single-dose EPO treatment was not as effective. At 3 months after neonatal stroke, there was no longer a difference in hemispheric volume between rats treated with a single dose of EPO and vehicle-treated rats. There was also no cognitive improvement, with no differences in any components of the Morris water maze between rats treated with a single dose and vehicle-treated rats. The underlying mechanisms responsible for neuroprotection at earlier time points may not persist this far out after a single dose of EPO. Endogenous EPO is upregulated after injury [10], and this single dose of EPO immediately after injury may not be sufficient to overcome any endogenous mechanisms at this late time point. In addition, newly generated cells may not maintain the intracellular signaling or perfusion to survive.

EPO appears to function via multiple mechanisms, and while single-dose treatment may decrease apoptosis and increase cell survival initially, it may have little to no effect on long-term cell repair and incorporation into neural networks, or on later neurogenesis and cell proliferation. Following hypoxia and stroke, neuronal transcription factor HIF-1 $\alpha$ expression is stabilized and increases expression of downstream targets that include EPO and VEGF [10], initiating pathways for neuroprotection, angiogenesis, and repair. EPO leads to phosphorylation of Janus kinase 2 (JAK2), and eventually, phosphorylation and activation of the mitogen-activated protein kinase (MAPK), extracellular signal-regulated kinase (ERK1/2), as well as the phosphatidylinositol 3-kinase (PI3K)/Akt (protein kinase B) pathway and signal transducer and activator of transcription 5 (STAT5), which are critical in cell survival. For example, EPO increases the rate and quantity of STAT5 expression, resulting in upregulation of anti-apoptotic genes such as $\mathrm{Bcl}-\mathrm{xL}[23,31-$ 34] and NF- $\kappa B$ [33]. Akt also inactivates $\mathrm{Bcl} 2$ family member Bad and limits inflammation [35]. In addition to anti-apoptotic effects, the ERK pathway has anti-inflammatory effects and increases neurogenesis while altering cell fate commitment [36, 37], implicating this pathway in repair processes. Following injury, tissue protective and reparative effects of EPO-stimulated ERK activation have been shown in adult models of brain injury $[35,36$, 38]. Increases in angiogenesis following injury may be necessary for long-term survival of injured or newly generated cells, which appears to be effects of both EPO and its interaction with VEGF [39]. For example, EPO-treated rats had increased VEGF and brain-derived neurotrophic factor levels after stroke, as well as angiogenesis and neurogenesis, with induced neuroblast migration to these regions [7]. PI3K also mediates increased angiogenesis in the ischemic boundary following ischemic stroke [40]. However, the effect and time course of phosphorylation and activation of these kinases in the immature brain and their effect on cytokine production following stroke are not clear.

EPO does not appear to protect against early injury in the first $6 \mathrm{~h}$ [18], rather at later time points, suggesting a delay is required for the responsible mechanisms. This may be related to upregulation of EPO-R, synthesis of protein, or activation of a cascade that results in increases in cell number, function, and perfusion. For example, EPO has also been found to inhibit neointimal hyperplasia after arterial injury by acting on injured vessels and mobilizing endothelial progenitor cells to the neo-endothelium [41], promoting angiogenesis and repair of blood vessels. In addition to decreased apoptosis, increased neurogenesis and angiogenesis, cell repair may be an important component of these histological changes and long-term cognitive improvements. EPO may work by mechanisms similar to those seen with environmental enrichment, which is known to have effects on neuronal plasticity and cognitive function. Enrichment includes exposing these animals to tunnels, platforms, toys, and running wheels that potentiate social interaction and increase stimulation [42]. These factors result in structural changes in neural cells, and possibly volume of brain structures, with increased neurogenesis, synaptogenesis, dendritic branching, and increased neurotrophic factors in the hippocampus, striatum, and cortex [43-45]. Enrichment increases brain-derived neurotrophic factor following brain injury [46, 47], although some studies suggest females may benefit from this more than males [48]. Daily enrichment also prevents spatial memory deficits after adult hypoxia-ischemia [49] and stroke [47, 50], and early housing in an enriched environment prevented some cognitive deficits after neonatal hypoxia-ischemia [51]. Young adult mice develop more differentiating neuroblasts, with increased neuronal survival in the dentate gyrus [52], and physical activity and enriched environments also increased proliferation of precursor cells in the adult hippocampus [53].

The Morris water maze is a validated test for spatial learning and memory [54]. Performance in the water maze often correlates with hippocampal function [55], but also requires intact vision and motor ability for completion of tasks. While there was no difference in cognitive function in rats treated with a single dose, EO-3 rats did show a trend toward escaping to the hidden platform in the place condition, suggesting improved learning over the 6 days of testing relative to other injured groups, and 
these rats also had significant improvement in memory, remembering the previous location of the platform in the probe trials. EO-3 rats also demonstrated improved vision and motor ability in the cue condition.

Performance in these cognitive tests correlated with total hippocampal volume, as it appears that this hippocampal injury resulted in spatial memory deficits that persisted into adulthood. In addition, behavioral findings on most components of the water maze correlated with striatal, neocortical, and primary visual cortical volume. The striatum is also involved with acquisition in complex maze tasks [56], while the neocortex was used as a marker of the sensorimotor cortex. It is difficult to determine how injuries to particular brain regions relate to spatial learning or memory deficits because of the strong intercorrelations among regional areas.

Given the evolution of injury over time, and the improvement seen with additional and later doses of EPO, it remains to be seen what therapeutic regimen results in the best long-term outcomes. Recent findings suggest that up to 3 doses of $5 \mathrm{U} / g$ show short-term improvement in apoptosis and gliosis after rat neonatal hypoxia-ischemia, with dose-dependent protection in a U-shaped manner [57]. Taken together with previous studies, our observations suggest that EPO may be useful both early, for its direct neuroprotective effect by preventing cell death, and late, influencing cell repair, progenitor cell fate, neurogenesis and migration. Perhaps by clarifying the mechanisms and timing of both repair and neurogenesis, the optimal dosing regimen to maximize long-term outcomes will become clear.

\section{Acknowledgments}

This work was supported by grant P50 NIH NINDS Program Project NS 35902; Johnson \& Johnson Pharmaceutical Research and Development, L.L.C., Raritan NJ, NS 33997, and March of Dimes Birth Defect Foundation 6-FY2006-465. D.M. is also supported by the National Scientific Foundation of China, grant numbers 30825039 and 30770748 .

\section{References}

1 Lynch JK, Nelson KB: Epidemiology of perinatal stroke. Curr Opin Pediatr 2001;13: 499-505.

-2 Lee J, Croen LA, Lindan C, Nash KB, Yoshida CK, Ferriero DM, Barkovich AJ, Wu YW: Predictors of outcome in perinatal arterial stroke: a population-based study. Ann Neurol 2005;58:303-308.

-3 McKinstry RC, Miller JH, Snyder AZ, Mathur A, Schefft GL, Almli CR, Shimony JS, Shiran SI, Neil JJ: A prospective, longitudinal diffusion tensor imaging study of brain injury in newborns. Neurology 2002;59:824-833.

4 Villa P, Bigini P, Mennini T, Agnello D, Laragione T, Cagnotto A, Viviani B, Marinovich $\mathrm{M}$, Cerami A, Coleman TR, Brines $\mathrm{M}$, Ghezzi P: Erythropoietin selectively attenuates cytokine production and inflammation in cerebral ischemia by targeting neuronal apoptosis. J Exp Med 2003;198:971-975.

-5 Agnello D, Bigini P, Villa P, Mennini T, Cerami A, Brines ML, Ghezzi P: Erythropoietin exerts an anti-inflammatory effect on the CNS in a model of experimental autoimmune encephalomyelitis. Brain Res 2002; 952:128-134.

6 Arvin B, Neville LF, Barone FC, Feuerstein GZ: The role of inflammation and cytokines in brain injury. Neurosci Biobehav Rev 1996; 20:445-452.

7 Wang L, Zhang Z, Wang Y, Zhang R, Chopp M: Treatment of stroke with erythropoietin enhances neurogenesis and angiogenesis and improves neurological function in rats. Stroke 2004;35:1732-1737.
8 Chong ZZ, Kang JQ, Maiese K: Angiogenesis and plasticity: role of erythropoietin in vascular systems. J Hematother Stem Cell Res 2002;11:863-871.

-9 Bernaudin M, Marti HH, Roussel S, Divoux D, Nouvelot A, MacKenzie ET, Petit E: A potential role for erythropoietin in focal permanent cerebral ischemia in mice. J Cereb Blood Flow Metab 1999;19:643-651.

$10 \mathrm{Mu}$ D, Chang YS, Vexler ZS, Ferriero DM: Hypoxia-inducible factor 1alpha and erythropoietin upregulation with deferoxamine salvage after neonatal stroke. Exp Neurol 2005;195:407-415.

11 Juul SE, Anderson DK, Li Y, Christensen RD: Erythropoietin and erythropoietin receptor in the developing human central nervous system. Pediatr Res 1998;43:40-49.

12 Sadamoto Y, Igase K, Sakanaka M, Sato K, Otsuka H, Sakaki S, Masuda S, Sasaki R: Erythropoietin prevents place navigation disability and cortical infarction in rats with permanent occlusion of the middle cerebral artery. Biochem Biophys Res Commun 1998; 253:26-32.

13 Aydin A, Genc K, Akhisaroglu M, Yorukoglu K, Gokmen N, Gonullu E: Erythropoietin exerts neuroprotective effect in neonatal rat model of hypoxic-ischemic brain injury. Brain Dev 2003;25:494-498.

14 Sola A, Wen TC, Hamrick SE, Ferriero DM: Potential for protection and repair following injury to the developing brain: a role for erythropoietin? Pediatr Res 2005;57:110R$117 \mathrm{R}$.
15 Sakanaka M, Wen TC, Matsuda S, Masuda S, Morishita E, Nagao M, Sasaki R: In vivo evidence that erythropoietin protects neurons from ischemic damage. Proc Natl Acad Sci USA 1998;95:4635-4640.

16 Brines ML, Ghezzi P, Keenan S, Agnello D, de Lanerolle NC, Cerami C, Itri LM, Cerami A: Erythropoietin crosses the blood-brain barrier to protect against experimental brain injury. Proc Natl Acad Sci USA 2000;97: 10526-10531.

-17 Kumral A, Ozer E, Yilmaz O, Akhisaroglu M, Gokmen N, Duman N, Ulukus C, Genc S, Ozkan H: Neuroprotective effect of erythropoietin on hypoxic-ischemic brain injury in neonatal rats. Biol Neonate 2003;83:224228.

18 Matsushita H, Johnston MV, Lange MS, Wilson MA: Protective effect of erythropoietin in neonatal hypoxic ischemia in mice. Neuroreport 2003; 14:1757-1761.

19 Sun Y, Zhou C, Polk P, Nanda A, Zhang JH: Mechanisms of erythropoietin-induced brain protection in neonatal hypoxia-ischemia rat model. J Cereb Blood Flow Metab 2004;24:259-270

-20 Spandou E, Papoutsopoulou S, Soubasi V, Karkavelas G, Simeonidou C, Kremenopoulos G, Guiba-Tziampiri O: Hypoxia-ischemia affects erythropoietin and erythropoietin receptor expression pattern in the neonatal rat brain. Brain Res 2004;1021:167172 .
Gonzalez/Abel/Almli/Mu/Wendland/ Ferriero 
-21 Solaroglu I, Solaroglu A, Kaptanoglu E, Dede S, Haberal A, Beskonakli E, Kilinc K: Erythropoietin prevents ischemia-reperfusion from inducing oxidative damage in fetal rat brain. Childs Nerv Syst 2003;19:19-22.

-22 Kumral A, Uysal N, Tugyan K, Sonmez A, Yilmaz O, Gokmen N, Kiray M, Genc S, Duman N, Koroglu TF, Ozkan H, Genc K: Erythropoietin improves long-term spatial memory deficits and brain injury following neonatal hypoxia-ischemia in rats. Behav Brain Res 2004;153:77-86.

-23 Sola A, Rogido M, Lee BH, Genetta T, Wen TC: Erythropoietin after focal cerebral ischemia activates the Janus kinase-signal transducer and activator of transcription signaling pathway and improves brain injury in postnatal day 7 rats. Pediatr Res 2005;57: 481-487.

24 Chang YS, Mu D, Wendland M, Sheldon RA, Vexler ZS, McQuillen PS, Ferriero DM: Erythropoietin improves functional and histological outcome in neonatal stroke. Pediatr Res 2005;58:106-111.

25 Derugin N, Wendland M, Muramatsu K, Roberts TP, Gregory G, Ferriero DM, Vexler ZS: Evolution of brain injury after transient middle cerebral artery occlusion in neonatal rats. Stroke 2000;31:1752-1761.

26 Mu D, Jiang X, Sheldon RA, Fox CK, Hamrick SE, Vexler ZS, Ferriero DM: Regulation of hypoxia-inducible factor lalpha and induction of vascular endothelial growth factor in a rat neonatal stroke model. Neurobiol Dis 2003; $14: 524-534$.

27 Hagberg H, Bona E, Gilland E, Puka-Sundvall $\mathrm{M}$ : Hypoxia-ischaemia model in the 7day-old rat: possibilities and shortcomings. Acta Paediatr Suppl 1997;422:85-88.

28 Regeur L, Pakkenberg B: Optimizing sampling designs for volume measurements of components of human brain using a stereological method. J Microsc 1989;155:113121.

29 Paxinos G, Watson C: The Rat Brain in Stereotaxic Coordinates. San Diego, Elsevier Academic Press, 2005.

-30 Gonzalez FF, McQuillen P, Mu D, Chang Y, Wendland M, Vexler Z, Ferriero DM: Erythropoietin enhances long-term neuroprotection and neurogenesis in neonatal stroke. Dev Neurosci 2007;29:321-330.

- 31 Digicaylioglu M, Lipton SA: Erythropoietinmediated neuroprotection involves crosstalk between Jak 2 and NF-kappaB signalling cascades. Nature 2001;412:641-647.

\$2 Wen TC, Sadamoto Y, Tanaka J, Zhu PX, Nakata K, Ma YJ, Hata R, Sakanaka M: Erythropoietin protects neurons against chemical hypoxia and cerebral ischemic injury by upregulating bcl-xl expression. J Neurosci Res 2002;67:795-803.

- 33 Shingo T, Sorokan ST, Shimazaki T, Weiss S: Erythropoietin regulates the in vitro and in vivo production of neuronal progenitors by mammalian forebrain neural stem cells. J Neurosci 2001;21:9733-9743.
34 Zhang F, Wang S, Cao G, Gao Y, Chen J: Signal transducers and activators of transcription 5 contributes to erythropoietin-mediated neuroprotection against hippocampal neuronal death after transient global cerebral ischemia. Neurobiol Dis 2007;25:4553 .

- 35 Yin D, Kawabata H, Tcherniamtchouk O, Huynh T, Black KL, Koeffler HP: Glioblastoma multiforme cells: expression of erythropoietin receptor and response to erythropoietin. Int J Oncol 2007;31:1193-1198.

36 Lee ST, Chu K, Sinn DI, Jung KH, Kim EH, Kim SJ, Kim JM, Ko SY, Kim M, Roh JK: Erythropoietin reduces perihematomal inflammation and cell death with eNOS and STAT3 activations in experimental intracerebral hemorrhage. J Neurochem 2006;96: 1728-1739.

37 Park MH, Lee SM, Lee JW, Son DJ, Moon DC, Yoon DY, Hong JT: Erk-mediated production of neurotrophic factors by astrocytes promotes neuronal stem cell differentiation by erythropoietin. Biochem Biophys Res Commun 2006;339:1021-1028.

38 Kilic U, KilicE, Soliz J, BassettiCI, Gassmann M, Hermann DM: Erythropoietin protects from axotomy-induced degeneration of retinal ganglion cells by activating ERK-1/-2 . FASEB J 2005;19:249-251.

39 Zachary I: Neuroprotective role of vascular endothelial growth factor: signalling mechanisms, biological function, and therapeutic potential. Neurosignals 2005;14:207-221.

40 Wang L, Zhang ZG, Zhang RL, Gregg SR, Hozeska-Solgot A, LeTourneau Y, Wang Y, Chopp M: Matrix metalloproteinase 2 (MMP2) and MMP9 secreted by erythropoietin-activated endothelial cells promote neural progenitor cell migration. J Neurosci 2006;26:5996-6003

41 Urao N, Okigaki M, Yamada H, Aadachi Y, Matsuno K, Matsui A, Matsunaga S, Tateishi K, Nomura T, Takahashi T, Tatsumi T, Matsubara $\mathrm{H}$ : Erythropoietin-mobilized endothelial progenitors enhance reendothelialization via Akt-endothelial nitric oxide synthase activation and prevent neointimal hyperplasia. Circ Res 2006;98:1405-1413.

-42 van Praag H, Kempermann G, Gage FH: Neural consequences of environmental enrichment. Nat Rev Neurosci 2000;1:191-198.

43 Lambert TJ, Fernandez SM, Frick KM: Different types of environmental enrichment have discrepant effects on spatial memory and synaptophysin levels in female mice. Neurobiol Learn Mem 2005;83:206-216.

44 Bennett JC, McRae PA, Levy LJ, Frick KM: Long-term continuous, but not daily, environmental enrichment reduces spatial memory decline in aged male mice. Neurobiol Learn Mem 2006;85:139-152.

45 Fan Y, Liu Z, Weinstein PR, Fike JR, Liu J: Environmental enrichment enhances neurogenesis and improves functional outcome after cranial irradiation. Eur J Neurosci 2007;25:38-46.
46 Segovia G, Del Arco A, de Blas M, Garrido P, Mora F: Effects of an enriched environment on the release of dopamine in the prefrontal cortex produced by stress and on working memory during aging in the awake rat. Behav Brain Res 2008;187:304-311.

47 Gobbo OL, O’Mara SM: Impact of enrichedenvironment housing on brain-derived neurotrophic factor and on cognitive performance after a transient global ischemia. Behav Brain Res 2004;152:231-241.

$\checkmark 48$ Chen X, Li Y, Kline AE, Dixon CE, Zafonte $\mathrm{RD}$, Wagner AK: Gender and environmental effects on regional brain-derived neurotrophic factor expression after experimental traumatic brain injury. Neuroscience 2005; 135:11-17.

49 Pereira LO, Arteni NS, Petersen RC, da Rocha AP, Achaval M, Netto CA: Effects of daily environmental enrichment on memory deficits and brain injury following neonatal hypoxia-ischemia in the rat. Neurobiol Learn Mem 2007;87:101-108.

-50 Dahlqvist P, Ronnback A, Bergstrom SA, Soderstrom I, Olsson T: Environmental enrichment reverses learning impairment in the Morris water maze after focal cerebral ischemia in rats. Eur J Neurosci 2004;19: 2288-2298.

-51 Pereira LO, Strapasson AC, Nabinger PM, Achaval M, Netto CA: Early enriched housing results in partial recovery of memory deficits in female, but not in male, rats after neonatal hypoxia-ischemia. Brain Res 2008; 1218:257-266.

52 Llorens-Martin MV, Rueda N, MartinezCue C, Torres-Aleman I, Florez J, Trejo JL: Both increases in immature dentate neuron number and decreases of immobility time in the forced swim test occurred in parallel after environmental enrichment of mice. Neuroscience 2007; 147:631-638.

53 Steiner B, Zurborg S, Horster H, Fabel K, Kempermann G: Differential 24 h responsiveness of Prox1-expressing precursor cells in adult hippocampal neurogenesis to physical activity, environmental enrichment, and kainic acid-induced seizures. Neuroscience 2008;154:521-529.

54 Altemus KL, Almli CR: Neonatal hippocampal damage in rats: long-term spatial memory deficits and associations with magnitude of hippocampal damage. Hippocampus 1997;7:403-415.

55 Almli CR, Levy TJ, Han BH, Shah AR, Gidday JM, Holtzman DM: BDNF protects against spatial memory deficits following neonatal hypoxia-ischemia. Exp Neurol 2000;166:99-114.

56 Pistell PJ, Nelson CM, Miller MG, Spangler EL, Ingram DK, Devan BD: Striatal lesions interfere with acquisition of a complex maze task in rats. Behav Brain Res 2008.

57 Kellert BA, McPherson RJ, Juul SE: A comparison of high-dose recombinant erythropoietin treatment regimens in brain-injured neonatal rats. Pediatr Res 2007;61:451-455. 